\title{
Assessment of mutilans-like hand deformities in chronic inflammatory joint diseases. A radiographic study of 52 patients
}

\author{
E A Belt, K Kaarela, M J Kauppi, H A Savolainen, H J Kautiainen, M U K Lehto
}

\begin{abstract}
Objectives-To evaluate patients with mutilans-like hand deformities in chronic inflammatory joint diseases and to determine radiographic scoring systems for arthritis mutilans (AM).

Methods-A total of 52 patients with severe hand deformities were collected during 1997. A Larsen hand score of 0-110 was formed to describe destruction of the hand joints. Secondly, each ray of the hand was assessed individually by summing the Larsen grade of the wrist and the grades of the MCP and PIP joints. When the sum of these grades was $\geqslant 13$, the finger was considered to be mutilated. A mutilans hand score of 0-10 was formed according to the number of mutilans fingers. Surgical treatment and spontaneous fusions were recorded.
\end{abstract}

Results-The study consisted of 22 patients with juvenile rheumatoid arthritis (JRA), nine with rheumatoid factor (RF) positive and 13 with RF negative arthritis, 27 patients with RF positive $R A$, and three adult patients with other diagnoses. The mean age of patients with adult rheumatic diseases was 27 years at the onset of arthritis. The mean disease duration in all patients was 30 years. The mean Larsen hand score was 93. Four patients had no mutilans fingers and in 15 patients all 10 fingers were mutilated. The Larsen hand score of 0-110 and the mutilans hand score of $0-10$ correlated well $\left(r_{\mathrm{s}}=0.90\right)$. Fourteen patients showed spontaneous fusions in the peripheral joints. A total of 457 operations were performed on 48 patients. Conclusion-Both the Larsen hand score of 0-110 and the mutilans hand score of 0-10 improve accuracy in evaluating mutilans-like hand deformities, but in unevenly distributed hand deformities the mutilans hand score is better in describing deformation of individual fingers. (Ann Rheum Dis 1999;58:250-252)

The terms arthritis mutilans (AM), La Main en Lorgnette, and resorptive arthropathy are often used as synonyms to describe severe multijoint deformities of the hands in patients with chronic polyarthritis. ${ }^{1-6}$ Characteristic features of AM consist of shortened fingers with excessive skin folds, hypermobile joints, and digits that can be elongated by traction. ${ }^{1-6}$ Radiographically, AM is characterised by the presence of severe resorption of the joint and bone, commencing at the articular surface or its margins and spreading distally and proximally. ${ }^{1-4}$ Pathogenesis of the disorder is unknown.

AM usually occurs in rheumatoid arthritis (RA) and psoriatic and chronic reactive arthritis, but it has also been described in juvenile rheumatoid arthritis (JRA) and mixed connective tissue disease (MCTD). ${ }^{1-6}$ The prevalence of resorptive arthropathy has been reported to be $5 \%$ in both RA and psoriatic arthritis, $^{25}$ but unknown in JRA. Mody defined a scoring system for the condition using the Larsen method and suggested a range of scores of $0-100$ for the hands (sum of all metacarpophalangeal (MCP) and proximal interphalangeal (PIP) joints and the interphalangeal (IP) joint of the thumb), 0-10 for the wrists and $0-50$ for the feet. ${ }^{57}$ The aim of this study was to evaluate our patients with clinically detected mutilans-like hand deformities and to develop a new radiographic method for describing AM.

\section{Methods}

Based on the clinical findings and hand radiographs, 52 patients with mutilans-like hand deformities were collected among patients visiting rheumatological (MJK), orthopaedic $(\mathrm{EAB})$, and paediatric units (HAS) of the Rheumatism Foundation Hospital during 1997. Severe deformity and some instability or telescoping of the finger(s) was a prerequisite, and the choice was based on clinical judgment.

In the year 1997, the grade of destruction was assigned by the Larsen method. ${ }^{7}$ Hand joints of all the patients were evaluated by $\mathrm{EAB}$; foot radiographs were available in 43 of 52 patients. In establishing a Larsen hand score of 0-110, destruction in the wrists, MCP I-V joints, and PIP II-V joints including IP I joints was graded and summed. ${ }^{57}$ Secondly, the frequency of resorptive arthropathy was evaluated individually, ray by ray, by summing the Larsen grade of the wrist and the grades of the MCP and PIP joints. In joints operated on, the last preoperative radiographs was evaluated. The term mutilans finger was established when the sum of these grades in one ray was $\geqslant 13$ (maximum 15). A mutilans hand score of 0-10 was formed according to the number of mutilans fingers. Spontaneous fusions were recorded both clinically and radiographically. Data on the surgical procedures were obtained from patient documents and radiographs.

In statistical analysis the Mann-Whitney test was used to show difference between patient groups. Correlations were performed using Spearman's coefficient. 
Table 1 Characteristics data of 52 patients with arthritis mutilans hand deformities

\begin{tabular}{|c|c|c|c|}
\hline Diagnosis & $\begin{array}{l}\text { Number of } \\
\text { patients } \\
\text { female/male }\end{array}$ & $\begin{array}{l}\text { Age at onset } \\
\text { of diagnosis } \\
\text { mean (SD) }\end{array}$ & $\begin{array}{l}\text { Duration of } \\
\text { disease mean } \\
(S D)\end{array}$ \\
\hline \multicolumn{4}{|c|}{ Juvenile rheumatoid arthritis } \\
\hline RF positive & $8 / 1$ & $12(4)$ & $27(7)$ \\
\hline RF negative & $10 / 3$ & $5(5)$ & $36(14)$ \\
\hline \multicolumn{4}{|l|}{ Rheumatoid } \\
\hline arthritis & $26 / 1$ & $27(10)$ & $29(9)$ \\
\hline Other & $1 / 2$ & $23(2)$ & $23(10)$ \\
\hline
\end{tabular}

\section{Results}

The study consisted of 22 patients with JRA including nine rheumatoid factor (RF) positive patients (defined by the Waaler-Rose method) and 13 RF negative, and 27 patients with RF positive adult onset RA, two patients with spondyloarthropathy (one HLA-B 27 positive, the other HLA-B 27 negative), and one with MCTD. The age at onset of the disease varied from a mean of five (range 0.4-15) years in patients with RF negative JRA to 27 (16-58) years in patients with RF positive RA, and the mean age of the adult onset rheumatic diseases was 27 years. Eighty seven per cent of patients were women. In 1997 the mean disease duration was 30 (10-61) years. Table 1 gives details of the subjects.

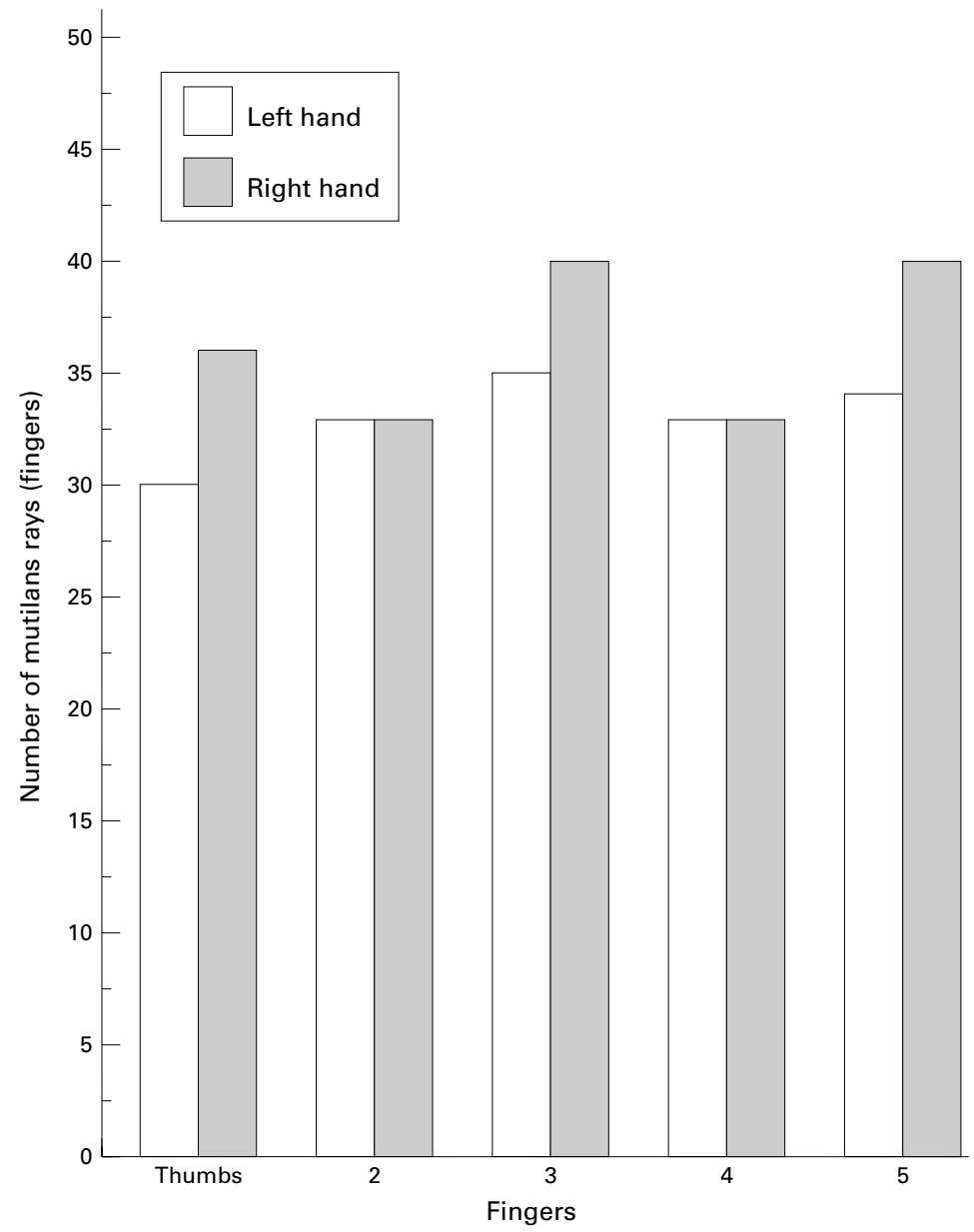

Figure 1 Distribution of mutilans fingers in 52 patients with chronic inflammatory joint diseases. In assessment of the mutilans finger (ray) the Larsen grades of the wrist, metacarpophalangeal, and proximal interphalangeal joints (including the interphalangeal joint of the thumb) are summed, and the number of the fingers (rays) with summed grades $\geqslant 13$ (maximum 15) is presented.
The mean Larsen hand score of $0-110$ in all patients was 93 (range 61-110); lowest (92) in patients with RF positive RA and highest (96) in patients with RF positive JRA. The Larsen hand score was $\geqslant 90$ in 34 of $52(65 \%)$ of the patients. Four patients had no mutilans fingers radiographically and in 15 patients all 10 fingers were mutilated. The distribution of mutilans fingers is presented in figure 1 showing no significant difference in the frequencies of AM among fingers. Figure 2 shows the distribution of mutilans hand scores in different patient groups. In those four patients having no mutilans fingers, the Larsen hand score was also lowest (range 61-71). The Larsen hand score of $0-110$ correlated well with the mutilans hand score of $0-10\left(r_{\mathrm{s}}=0.90 ; 95 \% \mathrm{CI}\right.$ $0.82,0.94)$. No significant difference in mutilans hand score was found between patients with RF positive or negative JRA or between patients with JRA and those with RA.

Destruction of hand joints was symmetric in all patients, except in the two with spondyloarthropathy. Symmetric forefoot destruction was present in the same patients. Destruction of the wrist joint occurred frequently, and 50 of 52 patients showed significant destruction of the wrists with a wrist score (summed Larsen grades of two wrists) of $\geqslant 7$; in 42 of 52 patients the wrist score was 10 .

In addition to resorptive destruction, 14 patients had spontaneous fusions in the peripheral joints. Two patients had a unilateral fusion of the wrist joint, eight had 15 spontaneous PIP fusions, and additionally one IP fusion was observed. In the foot, nine spontaneous metatarsophalangeal (MTP) joint fusions were detected in five patients, whereas the IP pedis was spontaneously fused in 10 toes of nine patients. Spontaneous fusions were found in 4 of 13 patients with RF negative JRA (31\%), in 2 of 9 patients with RF positive JRA (22\%), in 6 of 27 patients with RF positive RA (22\%), and in two patients with other diagnoses.

A high number of operations was performed; one patient with JRA underwent surgery 25 times. On 52 patients, 457 operations were performed (nine procedures/patient). No surgery was performed in four patients. A total of 128 arthroplasties of hip, knee, elbow, or shoulder joints were performed on 41 patients. Wrists were fused in 32 patients ( 26 on the right side and 28 on the left), MCP arthroplasties were performed in 12 patients, and MCP I, IP I, PIP and distal interphalangeal (DIP) joints were fused in 29 patients. Seven patients underwent surgery in the first carpometacarpal joint.

\section{Discussion}

RF positive RA is a continually progressive disease. ${ }^{89}$ The prevalence of AM among patients with RA has been reported to be $5 \%$, based on hospital material. ${ }^{1}$ No incidence data on AM in patients with RA or JRA have been reported, probably because the follow up period should be especially long, and only few prospective long term series exist. ${ }^{10}$

The term AM is not defined exactly and presence of the disorder is dependent on the clinical judgment. Better definition of AM is needed, 


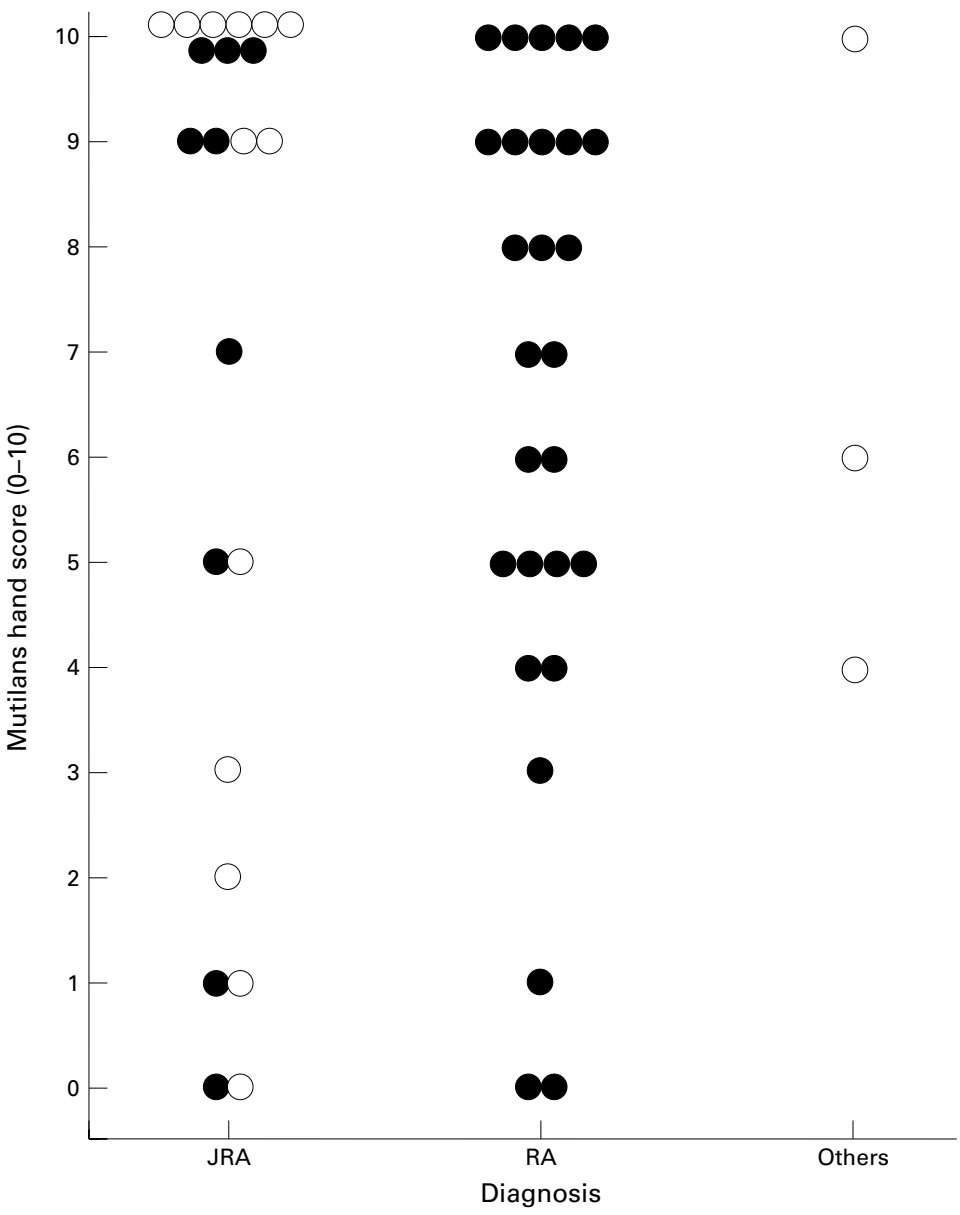

Figure 2 Distribution of mutilans scores of 0-10 in different diagnostic groups at the end point. In forming the mutilans score, the mutilans fingers of a patient are summed. Black circle presents a patient with $R F$ positive and white circle with $R F$ negative disease.

and if based on radiographic assessment it would be reproducible. The validity of the Larsen method has frequently been tested. The Larsen hand score of $0-110$ and the mutilans hand score of $0-10$ are based on differently summed Larsen grades. Both these scores are useful, but individual fingers are distinctly better considered with the mutilans hand score, especially in hands with unevenly distributed deformities.

The mean age of adult onset rheumatic diseases was low at disease onset (mean 27 years) and the disease duration of the whole series was long (30 years), also compared with the results of Mody and Meyers (age 49, duration 20 years), Yosida et al (41 and 20 years) Katayama et al (37 and 26 years), respectively. ${ }^{51011}$ The disease duration was long for JRA, considering that about $60 \%$ of JRA patients are symptom free after 10 years. ${ }^{12}$ All our patients with JRA had polyarticular disease and $41 \%$ were $\mathrm{RF}$ positive. The proportion of RF positivity in patients with JRA in clinic based studies is usually about $5 \% .{ }^{13}$ Patients with RF positive JRA seldom attain remission. ${ }^{14}$

Severe resorptive changes were present in most MCP and PIP joints. Our opinion is that both these joints must be severely destroyed, before the digit is sufficiently unstable and shortened to allow AM to be considered. In the rheumatoid hand, long term destruction is more pronounced proximally than distally, ${ }^{9}$ and therefore destruction of PIP joints is essential in AM development. If PIP joints are severely destroyed, so are often MCP joints and the wrists, too. ${ }^{10}$

Wrist fusion is the only means of interfering in shortening of the carpus and prevents resorption of the carpals, leading to loss of stability between the bases of the digits. ${ }^{3}$ To emphasise the importance of the wrist for whole hand function and development of AM deformity, the grade of destruction of the wrist was included in assessment of all individual digits (rays) and in the mutilans hand score of $0-10$.

The disability caused by AM is the result of finger shortening, instability of the joints, and difficulty in pinching. ${ }^{3}$ Fusions of PIP, MCP I, and IP I joints often require bone grafting in AM to restore the length of the finger. ${ }^{3}$ If the joint is fused before severe resorption, the procedure is much easier to perform. The patients had developed AM deformities despite active surgical treatment and rheumatological follow up. As we deal with resorptive arthropathy, the proportion of patients $(27 \%)$ with spontaneous fusion(s) of the peripheral joints was surprising. Most often it occurred in the IP joint of the big toe. In JRA a spontaneous fusion is not a rarity. Laaksonen reported these in $32 \%$ of 517 patients, predominantly in wrists. ${ }^{15}$ No conclusion could be drawn of the possible preventive role of surgical or antirheumatic treatment; however, we feel that untreated the situation would probably be even worse.

At our hospital, which is specialised in the treatment of chronic inflammatory joint diseases, AM deformities are occasionally encountered. As AM is poorly defined and based on the clinician's individual impression, we introduce a new radiographic definition for AM.

1 Swezey RL, Bjarnason DM, Alexander SJ, Forrester DB. Resorptive arthropathy and the opera-glass hand syndrome. Semin Arthritis Rheum 1972-1973;2:191-244.

2 Moll JMH, Wright V. Psoriatic arthritis. Semin Arthritis Rheum 1973;3:55-78.

3 Nalebuff EA, Garrett J. Opera-glass hand in rheumatoid arthritis. J Hand Surg 1976;1:210-20.

4 Alarcon-Segovia D, Uribe-Uribe O. Mutilans-like arthropathy in mixed connective tissue disease. Arthritis Rheum 1979;22:1013-18.

5 Mody GM, Meyers OL. Resorptive arthropathy in rheumatoid arthritis. J Rheumatol 1988;15:1075-7.

toid arthritis. J Rheumatol 1988;15:1075-7. O’Neill TW, Evison G, Ghalla AK. Pseudoarthroplastic
in arthritis mutilans. Br J Rheumatol 1992;31:559-60.

7 Larsen A, Dale K, Eek M. Radiographic evaluation of rheuLarsen A, Dale K, Eek M. Radiographic evaluation of rheu-
matoid arthritis and related conditions by standard reference films. Acta Radiol Diagn 1977;18:481-91.

8 Kaarela K, Kautiainen H. Continuous progression of radiological destruction in seropositive rheumatoid arthritis. J Rheumatol 1997;24:1285-7.

9 Belt EA, Kaarela K, Lehto MUK. Destruction and reconstruction of hand joints in rheumatoid arthritis. A 20-year followup study. J Rheumatol 1998;25:459-61.

10 Yosida M, Belt EA, Kaarela K, Kauppi MJ, Shimamura T. Prevalence of mutilans-like hand deformities in patients with seropositive rheumatoid arthritis. A 20-year follow-up study. Scand J Rheumatol (in press)

11 Katayama K, Takasugi K, Kondo Y, Ueda S-I, Oyama T, Okuda Y, et al. Sequential observation of generalized jointresorptive phenomena in systemic mutilating rheumatoid

12 Flatø B, Aasland A, Vinje O, Førre Ø. Outcome and predictive factors in juvenile rheumatoid arthritis and juvenile spondyloarthropathy. J Rheumatol 1998;25:366-75.

13 Michels H, Häfner R, Morhart R, Schuhmann L, Truckenbrodt $\mathrm{H}$. Five year follow-up of a prospective cohort of uvenile chronic arthritis with recent onset. Clin Rheumatol 1987;6 (suppl 2):87-92.

14 Ansell BM. Juvenile chronic arthritis. Scand J Rheumatol 1987;16 (suppl 66):47-50.

15 Laaksonen AL. A prognostic study of juvenile rheumatoid arthritis. Analysis of 544 cases. Acta Paed Scand 1966;15 (suppl 166):1-163. 